Article

\title{
High-Power GaN-Based Vertical-Cavity Surface-Emitting Lasers with AlInN/GaN Distributed Bragg Reflectors
}

\author{
Masaru Kuramoto ${ }^{1, *}$, Seiichiro Kobayashi ${ }^{1}$, Takanobu Akagi ${ }^{1}$, Komei Tazawa ${ }^{1}$, \\ Kazufumi Tanaka ${ }^{1}$, Tatsuma Saito ${ }^{1}$ and Tetsuya Takeuchi ${ }^{2}$ \\ 1 R\&D Laboratories, Stanley Electric Co., Ltd., 1-3-1 Edanishi, Aoba-ku, Yokohama 225-0014, Japan; \\ seiichiro_kobayashi@stanley.co.jp (S.K.); takanobu_akagi@stanley.co.jp (T.A.); \\ komei_tazawa@stanley.co.jp (Ko.T.); kazufumi_tanaka@stanley.co.jp (Ka.T.); \\ tatsuma_saito@stanley.co.jp (T.S.) \\ 2 Faculty of Science and Technology, Meijo University,1-501 Shiogamaguchi Tenpaku-ku, Nagoya 468-8502, \\ Japan; take@meijo-u.ac.jp \\ * Correspondence: masaru_kuramoto@stanley.co.jp; Tel.: +81-45-910-2103
}

Received: 17 December 2018; Accepted: 20 January 2019; Published: 26 January 2019

\begin{abstract}
High-efficiency and high-power operation have been demonstrated for blue GaN-based vertical-cavity surface-emitting lasers (VCSELs) with AlInN/GaN distributed Bragg reflectors. The high-efficiency performance was achieved by introducing a novel $\mathrm{SiO}_{2}$-buried lateral index guide and adjusting the front mirror reflectivity. Lateral optical confinement has been shown to greatly lower the otherwise significant loss of transverse radiation exhibited by typical VCSELs based on GaN. Employing a long (10 $\lambda$ ) cavity can also enhance the output power, by lowering the thermal resistance of the VCSEL and increasing the operating current associated with thermal rollover. This modification, in conjunction with optimized front mirror reflectivity and a buried $\mathrm{SiO}_{2}$ lateral index guide, results in a blue VCSEL (in the continuous wave mode with an $8 \mu \mathrm{m}$ aperture at $20^{\circ} \mathrm{C}$ ) having a superior differential quantum efficiency value of $31 \%$ and an enhanced $15.7 \mathrm{~mW}$ output power. This unit also exhibits a relatively high output power of $2.7 \mathrm{~mW}$ at temperatures as high as $110^{\circ} \mathrm{C}$. Finally, a $5.5 \mu \mathrm{m}$ aperture VCSEL was found to generate a narrow divergence $\left(5.1^{\circ}\right)$ single-lobe far field pattern when operating at an output power of approximately $5 \mathrm{~mW}$.
\end{abstract}

Keywords: GaN-based VCSEL; AlInN/GaN DBR; lateral optical guide; internal loss; differential quantum efficiency; thermal resistance; small divergence angle

\section{Introduction}

GaN-based vertical-cavity surface-emitting lasers (VCSELs) are important in numerous applications, including adaptive laser headlamps [1-3], retinal scanning displays and visible light communication systems. VCSELs have numerous advantages, including the avoidance of catastrophic optical damage (COD), ready integration with two-dimensional arrays, minimal temperature dependence and circular output beams with limited divergence. It is especially important to avoid COD in automotive headlamp laser diodes to ensure safety, and it is also helpful if the lasing wavelength is not affected by temperature so that a stable beam color is obtained. Based on these requirements, a combination of blue VCSELs and phosphors are the most attractive light source for next-generation laser headlamps. Recently, some research groups have achieved continuous-wave (CW) operation of GaN-based VCSELs [3-11] and reported output power values of approximately $1 \mathrm{~mW}[7,10,12-14]$ and $4.2 \mathrm{~mW}$ [15]. However, further improvements in GaN-based VCSELs are required for applications such as laser headlamps. Figure 1 shows the relationship between light output powers (LOPs) and external 
differential quantum efficiencies $\left(\eta_{d}{ }^{F}\right)$ reported to date for GaN-based VCSELs [7,8,12,13,15-21]. Improving the output power of such devices evidently requires that the $\eta_{d}{ }^{F}$ value be increased. Our own group has recently reported an enhanced output power of $6 \mathrm{~mW}$, as a result of increasing $\eta_{d}{ }^{F}$ [20]. We have also demonstrated improvements in the thermal resistance of these units [21] in conjunction with CW operation, leading to an increased output power of $15.7 \mathrm{~mW}$. Section 2 of this paper discusses the process by which lowering both the front cavity mirror reflectivity and the internal loss results in a superior $\eta_{d}{ }^{F}$ value [20]. The high-temperature functioning of a blue VCSEL based on GaN and having a long cavity, in conjunction with a significant output power and minimal beam divergence, is demonstrated in Section 3 [21]. This paper summarizes prior publications by our group in Applied Physics Letters [20] and Applied Physics Express [21].

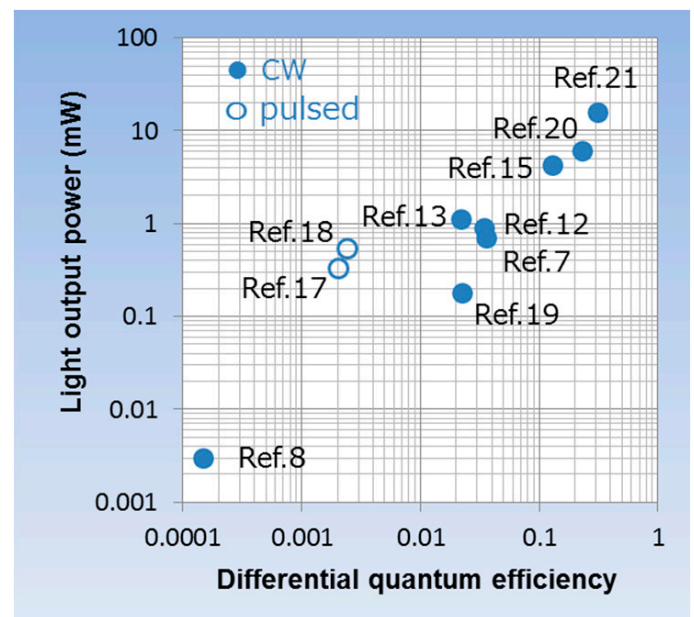

Figure 1. Light output power as a function of differential quantum efficiency for reported GaN-based VCSELs [7,8,12,13,15-21]. The open and closed circles indicate pulsed operation and CW operation, respectively.

\section{Enhancement of Differential Quantum Efficiency}

The $\eta_{d}{ }^{F}$ value obtained from the front side mirror for a VCSEL can be expressed as:

$$
\eta_{d}^{F}=\eta_{i} \times \frac{\alpha_{m}^{F}}{\alpha_{i}+\alpha_{m}^{F}+\alpha_{m}^{R}}
$$

where $\alpha_{i}$ is the internal loss, $\eta_{i}$ is the internal quantum efficiency, and $\alpha_{m}{ }^{F}$ and $\alpha_{m}{ }^{R}$ are the front and rear mirror losses, respectively [22]. Reducing the internal loss is important for enhancing $\eta_{d}{ }^{F}$. One potential reason for a low $\eta_{d}{ }^{F}$ is a high internal loss in the cavity. Most VCSELs based on GaN that have been reported in the literature thus far have achieved homogeneous current injection and current confinement by employing $\mathrm{SiO}_{2}$ apertures and intra-cavity contacts made of indium tin oxide (ITO), despite the anti-guiding that can result from such features [23]. Hashemi et al. [23] performed a theoretical analysis of the transverse radiation loss caused by a lateral anti-guiding structure and determined that the total internal loss could range from 50 to $70 \mathrm{~cm}^{-1}$ in a GaN-based VCSEL with a simple $\mathrm{SiO}_{2}$ aperture. They proposed several lateral optical confinement (LOC) structures to reduce the internal loss. Equation (1) shows that a low $\eta_{d}^{F}$ can also result from the cavity mirror design. Thus, the mirror reflectivity should be adjusted in accordance with variations of the optical gain and loss parameters. Reducing $\alpha_{i}$ allows more range in the mirror design and reduces the front mirror reflectivity. The present section describes a blue VCSEL based on GaN exhibiting greatly improved differential quantum efficiency, as a result of lowering the cavity mirror reflectivity and incorporating a $\mathrm{SiO}_{2}$-buried LOC structure. 
Figure 2 presents diagrams of a $\mathrm{SiO}_{2}$-buried VCSEL and a conventional $\mathrm{SiO}_{2}$ aperture, both of which were fabricated using metalorganic vapor phase epitaxy in conjunction with GaN substrates. Each unit comprised a 10.5-pair $\mathrm{SiO}_{2} / \mathrm{Nb}_{2} \mathrm{O}_{5}$ distributed Bragg reflector (DBR), a $4.5 \lambda$ cavity and a 46-pair AlInN/GaN DBR. A $75 \mathrm{~nm}$ p-GaN layer, $20 \mathrm{~nm}$ p- $\mathrm{Al}_{0.15} \mathrm{Ga}_{0.85} \mathrm{~N}$ electron blocking layer, $3 \mathrm{~nm}$ 5-pair GaInN/4 nm GaN multiple quantum well and $570 \mathrm{~nm}$ n-GaN layer were situated between the DBRs. In Figure 2a, the thickness of the $\mathrm{SiO}_{2}$ layer was $100 \mathrm{~nm}$ with an aperture diameter of $8 \mu \mathrm{m}$. A $20 \mathrm{~nm}$ ITO contact layer was deposited following fabrication of the conventional $\mathrm{SiO}_{2}$ aperture, following which a 10.5-pair $\mathrm{SiO}_{2} / \mathrm{Nb}_{2} \mathrm{O}_{5} \mathrm{DBR}$ and a $38 \mathrm{~nm} \mathrm{Nb}_{2} \mathrm{O}_{5}$ spacer layer were applied to the ITO such that a VCSEL cavity was obtained [11]. Assuming that a local shift of the resonance wavelength produces a corresponding change in the effective index [24], a calculation of the resonance wavelength difference gave a normalized effective index difference $\left(\Delta n_{\text {eff }} / n\right)$ of -0.025 for this structure, thus showing anti-guiding. Figure $2 \mathrm{~b}$ shows a buried $\mathrm{SiO}_{2}$ structure that was fabricated from an $8 \mu \mathrm{m}$ diameter region of the $\mathrm{p}-\mathrm{GaN}$ layer by reactive ion etching to a depth of $20 \mathrm{~nm}$. Following this, magnetron sputtering was employed to deposit a thin $(20 \mathrm{~nm}) \mathrm{SiO}_{2}$ film that was subsequently lifted off in a self-aligned manner. A $20 \mathrm{~nm}$ ITO contact layer was applied to the buried $\mathrm{SiO}_{2}$ and central current injection regions, followed by the deposition of a $38 \mathrm{~nm} \mathrm{Nb}_{2} \mathrm{O}_{5}$ spacer layer and a 10.5-pair $\mathrm{SiO}_{2} / \mathrm{Nb}_{2} \mathrm{O}_{5}$ DBR. The $\Delta n_{\text {eff }} / n$ value for this device was determined to be $2.6 \times 10^{-3}$, confirming lateral optical guiding. Both $n$ - and p-electrodes were fabricated in each structure, followed by polishing of the GaN substrate and coating of the substrate's back surface with an anti-reflection coating comprising four layers of a $\mathrm{SiO}_{2} / \mathrm{Nb}_{2} \mathrm{O}_{5}$ dielectric. Note that the substrate side is defined herein as the front of the device (see Figure 2). The reflectivity values for the 46-pair AlInN/GaN and 10.5-pair $\mathrm{SiO}_{2} / \mathrm{Nb}_{2} \mathrm{O}_{5}$ DBRs at $445 \mathrm{~nm}$ were determined to be $99.8 \%$ and $99.98 \%$, respectively. By way of comparison, a previous study produced a VCSEL having a 40-pair AlInN/GaN DBR and a $410 \mathrm{~nm}$ band that showed $99.7 \%$ reflectivity [11]. To obtain the same level of reflectivity in a VCSEL with a 445-nm band, the number of AlInN/GaN pairs must be increased, because the refractive index difference between AlInN and $\mathrm{GaN}$ is relatively small at longer wavelengths. In this work, the number of AlInN/GaN DBR pairs was also varied, over the range from 42 to 46 , so as to tune the reflectivity. The characteristics of the structures in Figure 2a,b were compared.

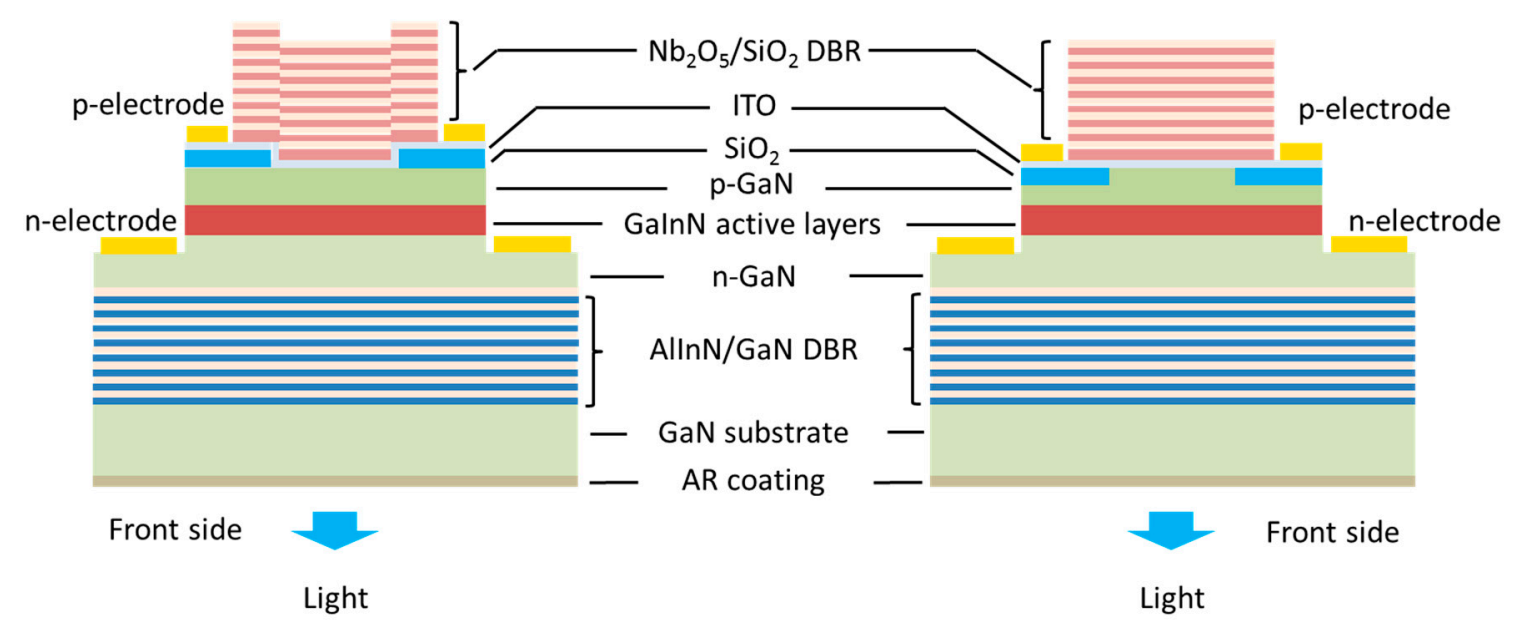

(a) Simple $\mathrm{SiO}_{2}$ aperture (conventional) structure

(b) $\mathrm{SiO}_{2}$-buried structure

Figure 2. Schematics of the fabricated blue VCSELs with (a) simple $\mathrm{SiO}_{2}$ aperture and (b) $\mathrm{SiO}_{2}$-buried lateral optical confinement structures. 
The AlInN/GaN DBR reflectivity value was calculated based on the front slope efficiency ratioed to the rear slope efficiency, in conjunction with pulsed operation [25]. A reflectivity of $99.98 \%$ was determined for the 10.5-pair $\mathrm{SiO}_{2} / \mathrm{Nb}_{2} \mathrm{O}_{5}$ DBR. The slope efficiency ratio can be expressed as:

$$
\frac{\eta_{s}^{F}}{\eta_{s}^{R}}=\frac{\left(1-R_{f}\right) \sqrt{R_{r}}}{\left(1-R_{r}\right) \sqrt{R_{f}}}
$$

where $\eta_{s}{ }^{F}$ and $\eta_{s}{ }^{R}$ are the front and rear slope efficiencies, and $R_{f}$ and $R_{r}$ are the front and rear reflectivity, respectively. In order to prevent thermal effects on the slope efficiency, these data were acquired with a pulse width of $300 \mathrm{~ns}$ and a $0.5 \%$ duty ratio. The time-resolved waveform of the current signal was obtained using a sampling oscilloscope (LeCroy 9374TM $1 \mathrm{GHz}$ bandwidth) and by measuring the average light output power with an optical power meter (ADCMT 8230). Figure 3a,b show the reflectivity and slope efficiency from the front side as functions of the number of AlInN/GaN DBR pairs. These VCSELs exhibited the lasing wavelength ranged from $440 \mathrm{~nm}$ to $443 \mathrm{~nm}$. From Figure $3 a$, it is evident that the reflectivity decreases as the number of DBR pairs decreases from 46 to 42 , corresponding to a change in the reflectivity from $99.8 \%$ to $99.5 \%$. The slight difference in reflectivity between the VCSELs with and without the LOC structure may be due to the In-plane distribution. This drop in reflectivity from $99.8 \%$ to $99.5 \%$ approximately doubles $\alpha_{m}{ }^{F}$ and therefore, based on Equation (1), gives a higher slope efficiency. Compared to the efficiency of a 46-pair AlInN/GaN DBR VCSEL with a conventional $\mathrm{SiO}_{2}$ aperture $(0.13 \mathrm{~W} / \mathrm{A})$, the efficiency increased by a factor of 4.7 (to $0.61 \mathrm{~W} / \mathrm{A}$ ) upon introducing the LOC structure, and was further improved, to a total factor of 6.7 (to $0.87 \mathrm{~W} / \mathrm{A}$ ), by additionally tuning the front cavity mirror. This represents the highest slope efficiency yet reported for a GaN-based VCSEL.

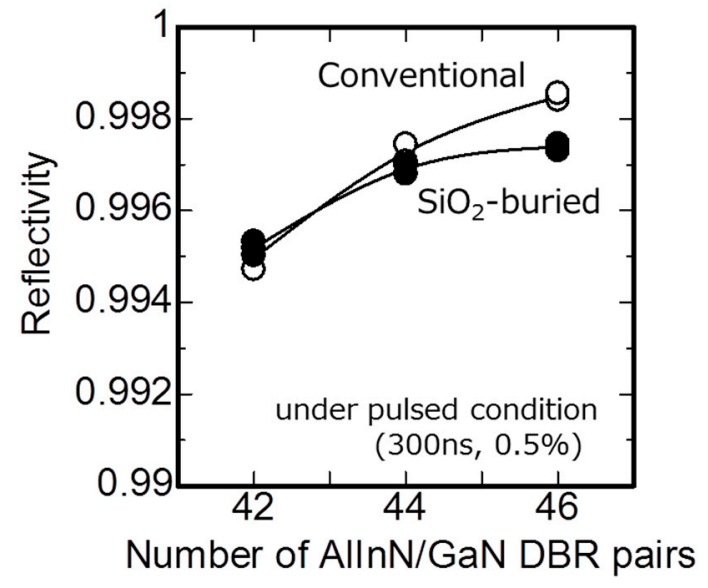

(a)

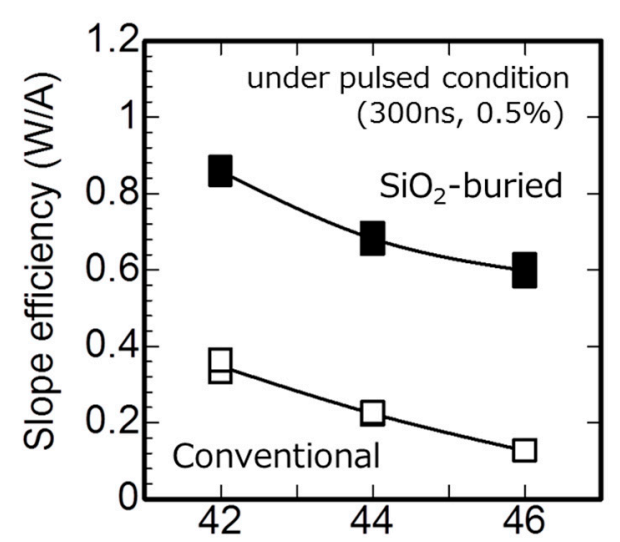

Number of AllnN/GaN DBR pairs

(b)

Figure 3. (a) Reflectivity of front mirror as a function of the number of AlInN/GaN DBR pairs. (b) Slope efficiency under pulsed conditions as a function of the number of AlInN/GaN DBR pairs. The open and closed symbols indicate the results obtained from VCSELs with a conventional $\mathrm{SiO}_{2}$ aperture and a $\mathrm{SiO}_{2}$-buried lateral optical confinement structure, respectively.

To evaluate the impact of reducing the internal loss by introducing the LOC structure, we analyzed the relationship between the mirror loss and the total external differential quantum efficiency 
$\left(\eta_{d}{ }^{\text {total }}\right)[26,27] . \eta_{d}{ }^{\text {total }}$ was calculated by determining both the front and rear side slope efficiencies. The mirror loss in a VCSEL, $\alpha_{m}$, can be expressed as:

$$
\alpha_{m}=\frac{1}{2 L_{e f f}} \ln \left(\frac{1}{R_{f} R_{r}}\right),
$$

where $L_{\text {eff }}$ is the total effective cavity length (equal to the physical length of the device plus the penetration depths into the front and rear mirrors). In this study, $L_{e f f}$ was calculated to be $1002 \mathrm{~nm}$ for our device, based on coupled-mode theory $[25,28]$. We used the calculated reflectivity value of $99.98 \%$ for the 10.5-pair $\mathrm{SiO}_{2} / \mathrm{Nb}_{2} \mathrm{O}_{5} \mathrm{DBR}$ as $R_{r}$ and the measured reflectivity of the front cavity mirror as $R_{f}$. Figure 4 shows the inverse of $\eta_{d}{ }^{\text {total }}$ as a function of the inverse of the mirror loss. The inverse of the internal quantum efficiency can be obtained from this plot as the intercept of a linear fit to the data, while the internal loss can be obtained from the slope of the line. From these data, the standard GaN-based VCSEL was determined to have an internal quantum efficiency of 0.5 together with an internal loss of $73 \mathrm{~cm}^{-1}$ in the absence of an LOC structure. As anticipated based on theoretical studies, the internal loss associated with this device was exceptionally high, at $73 \mathrm{~cm}^{-1}$ [23]. In contrast, the internal loss of the VCSEL incorporating the LOC structure was significantly reduced, to $23 \mathrm{~cm}^{-1}$. Thus, it was experimentally found that the impact on the transverse radiation loss was extremely high, namely a reduction of $50 \mathrm{~cm}^{-1}$, more than $2 / 3$ of the whole internal loss in the conventional VCSELs. In addition, a maximum $\eta_{d}^{\text {total }}$ of $32 \%$ was obtained from the $\mathrm{SiO}_{2}$-buried VCSEL with a 42-pair AlInN/GaN DBR under pulsed operation. This is also the highest efficiency ever reported for a GaN-based VCSEL. From Figure 4, the internal quantum efficiency of the VCSEL with the LOC structure was found to be 0.6. This value was also improved compared to that of the conventional VCSEL structure possibly due to the lower losses and threshold current densities. However, there is still room to improve the internal quantum efficiency as well as the internal loss value of blue GaN-based VCSELs.

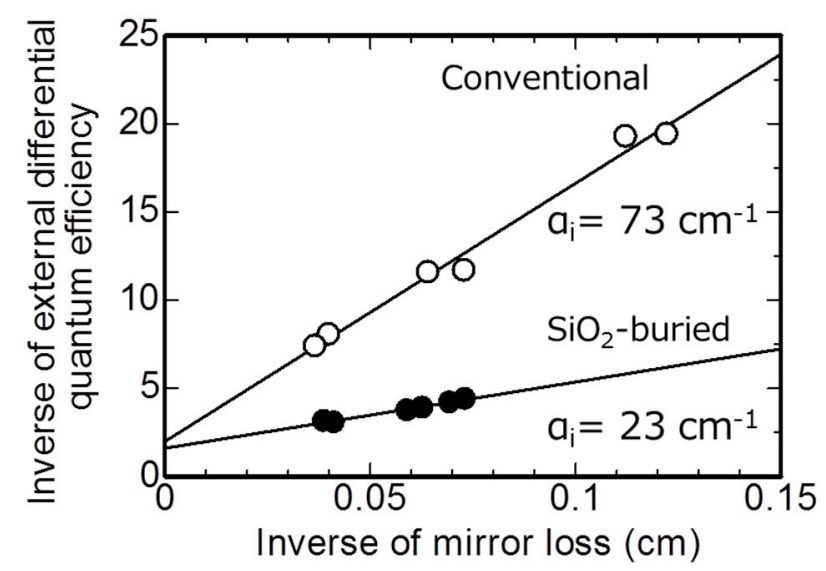

Figure 4. Inverse of external differential quantum efficiency as a function of the inverse of the mirror loss. The open and closed circles indicate the results obtained from VCSELs having a conventional $\mathrm{SiO}_{2}$ aperture and $\mathrm{SiO}_{2}$-buried lateral optical confinement structure, respectively.

In subsequent trials, VCSEL chips having LOC structures and $8 \mu \mathrm{m}$ apertures were assessed during $\mathrm{CW}$ operation after being placed on heat sinks made of $\mathrm{Cu}$ with their p-sides facing downwards (equivalent to flip-chip bonding). The front side light output power and voltage during room temperature CW operation are plotted against the injection current in Figure 5a. The threshold current, threshold current density and threshold voltage for the VCSEL with 42-pair AlInN/GaN DBR were determined to be $3 \mathrm{~mA}, 6.0 \mathrm{kA} / \mathrm{cm}^{2}$ and $4.7 \mathrm{~V}$, respectively. Although this device had the highest mirror loss among the fabricated VCSELs in this study, the threshold current and current density were relatively low owing to the low internal loss of $23 \mathrm{~cm}^{-1}$. A maximum output power of 
$6 \mathrm{~mW}$ was obtained. In the figure, it can be seen that the L-I curve exhibits kinks due to multimode lasing. The $8-\mu \mathrm{m}$ aperture was relatively large and hence higher-order modes were possible even with an extremely low $\Delta n_{\text {eff }} / n$ value of $2.6 \times 10^{-3}$ [14]. Multimode spectra were also acquired at a lasing wavelength of $441 \mathrm{~nm}$ using an optical spectrum analyzer (ANDO AQ-6315B), as shown in Figure 5b. The slope efficiency and the external differential efficiency for the front side were $0.64 \mathrm{~W} / \mathrm{A}$ and $23 \%$ in the vicinity of the threshold current under $\mathrm{CW}$ operation. Comparing these values to the results obtained under pulsed operation, the efficiencies were decreased due to thermal effects. From Figure 5a, the maximum power under CW operation when the number of DBR pairs was reduced. This is because the enhancement of the slope efficiency, rather than the threshold current increase, makes a large contribution to the maximum power value. Therefore, a combination of internal loss reduction and cavity mirror control is an effective approach for developing high power GaN-based VCSELs.

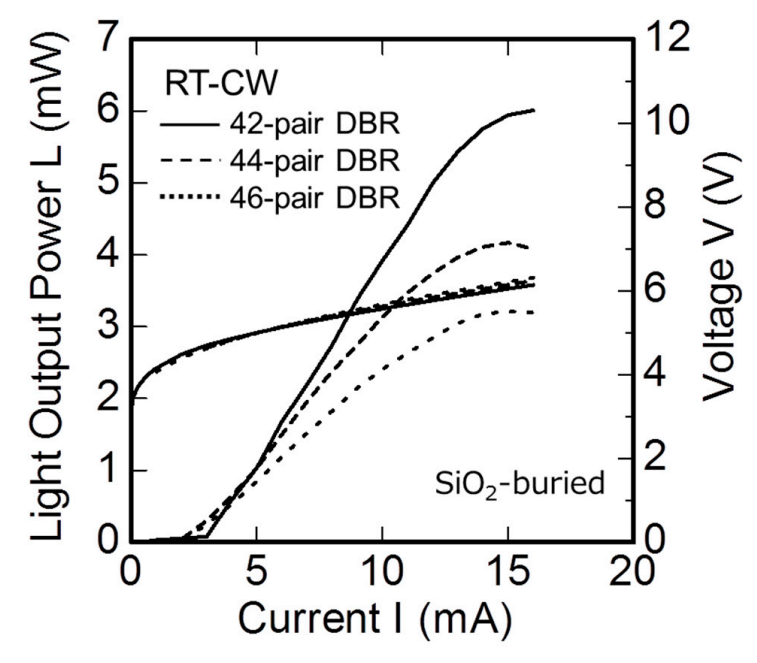

(a)

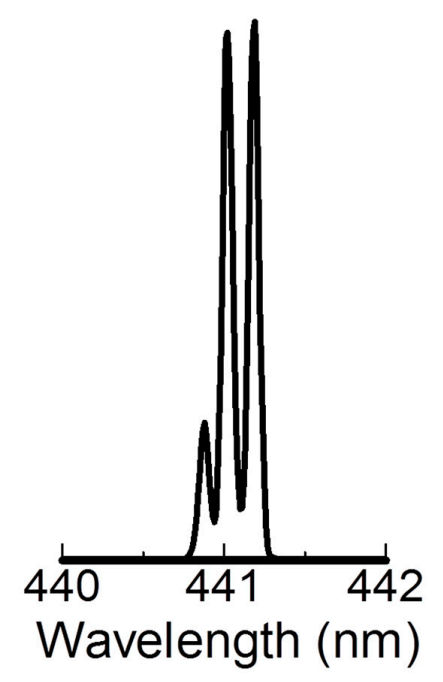

(b)

Figure 5. I-L/I-V characteristics (a) and emission spectrum (b) of the fabricated GaN-based VCSELs with 42 (solid line), 44 (dashed line), and 46 (dotted line) AlInN/GaN DBR pairs during CW operation at room temperature.

\section{High-Power and Narrow Divergent Beam Performance Using a Long Cavity Structure}

The data in Figure 5a demonstrate that thermal rollover limited the maximum output power, meaning that it is vital to lower the thermal resistance $\left(R_{t h}\right)$ to increase output power. Figure $2 \mathrm{~b}$ shows the structure having a 10.5-pair $\mathrm{SiO}_{2} / \mathrm{Nb}_{2} \mathrm{O}_{5}$ DBR, $4.5 \lambda$ cavity and 42-pair AlInN/GaN DBR, which was found to generate the highest output power. Because the DBR materials in this device, such as AlInN, have comparatively low thermal conductivities $[29,30]$, while GaN (the primary cavity material) possesses significant thermal conductivity [31,32], $R_{t h}$ is expected to be reduced as a result of implementing a long-cavity structure [33-35]. A previous theoretical study by Mei et al. [35] assessed the effect of cavity length on $R_{t h}$ in the case of a VCSEL based on GaN and having an AlInN/GaN DBR. This prior work employed a cylindrical model and estimated that a longer cavity would result in a $43 \%$ decrease in $R_{t h}$. Similarly, the present section demonstrates that incorporating a long cavity (of 10ג) results in the fabrication of a blue VCSEL based on GaN that exhibits a greater output power of $15.7 \mathrm{~mW}$. A $5 \lambda$-cavity VCSEL was also fabricated so as to compare the I-L data from the two different devices at various thermal resistance values and temperatures. The far field pattern (FFP) narrow divergent angle was also assessed to evaluate the effect of adding the long cavity.

The $5 \lambda$ - and $10 \lambda$-cavity devices comprised a 10.5-pair $\mathrm{SiO}_{2} / \mathrm{Nb}_{2} \mathrm{O}_{5} \mathrm{DBR}, 5 \lambda$ or $10 \lambda$ cavity and 42 or 41-pair AlInN/GaN DBR. As discussed in Section 2, the AlInN/GaN DBR mirror reflectivity in the $10 \lambda$-cavity VCSEL was lowered to offset any reduction in the slope efficiency stemming from the 
long cavity configuration. It should also be noted that, between the DBRs, the epitaxial structure was essentially identical to that shown in Figure $2 b$, and that the thicknesses of the n-GaN layers in the $5 \lambda$ and $10 \lambda$-cavity VCSELs were 660 and $1570 \mathrm{~nm}$, respectively. A $20 \mathrm{~nm}$ thick $\mathrm{SiO}_{2}$-buried structure was also incorporated into each device as a means of lowering the internal loss (see Figure 4). As described above (in Equation (2)), the AlInN/GaN DBR reflectivity values were calculated as the ratio of the front slope efficiency to the rear slope efficiency. The 41-pair and 42-pair AlInN/GaN DBRs were found to have reflectivities of $99.1 \%$ and $99.3 \%$, respectively. Prior to testing, each $8 \mu \mathrm{m}$ aperture VCSEL was bonded to a heat sink made of $\mathrm{Cu}$ with its $\mathrm{p}$-side facing downwards (equivalent to flip-chip bonding) and tests were performed in conjunction with $\mathrm{CW}$ conditions.

The I-L/I-V data obtained from a $5 \lambda$-cavity VCSEL between heat-sink temperatures of 20 and $100{ }^{\circ} \mathrm{C}$ are presented in Figure $6 \mathrm{a}$. The VCSEL showed high temperature lasing to a temperature of $100{ }^{\circ} \mathrm{C}$, in conjunction with a threshold voltage, threshold current density and threshold current $\left(I_{t h}\right)$ at $20^{\circ} \mathrm{C}$ of $5.1 \mathrm{~V}, 8.4 \mathrm{kA} / \mathrm{cm}^{2}$ and $4.2 \mathrm{~mA}$, respectively. This $I_{t h}$ is somewhat greater than the value in Figure $5 \mathrm{a}$ as a result of the increased front mirror loss that, in turn, stemmed from the decreased front mirror reflectivity. A combination of high efficiency and enhanced output power was obtained by lowering the front mirror reflectivity, although it should be noted that this raised the threshold current. A maximum output power of $8.2 \mathrm{~mW}$ at $20{ }^{\circ} \mathrm{C}$ and a $20 \mathrm{~mA}$ operating current are seen in Figure $6 \mathrm{a}$, and these results are attributed to the differential quantum efficiency $\left(\eta_{d}\right)$ of $25.4 \%$ and the significant slope efficiency $\left(\eta_{s}\right)$ of $0.71 \mathrm{~W} / \mathrm{A}$. Thermal rollover limited the maximum output power obtainable from the VCSEL, while the maximum output power and rollover operating current were both decreased as the heat sink temperature was increased. Therefore, it was anticipated that reducing the thermal resistance would result in a relatively high rollover current and thus provide an enhanced output power over a significant range of temperatures.

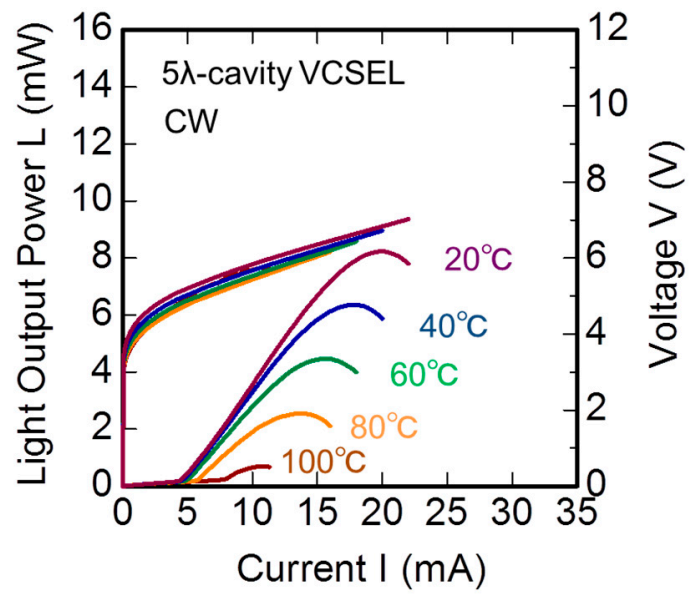

(a)

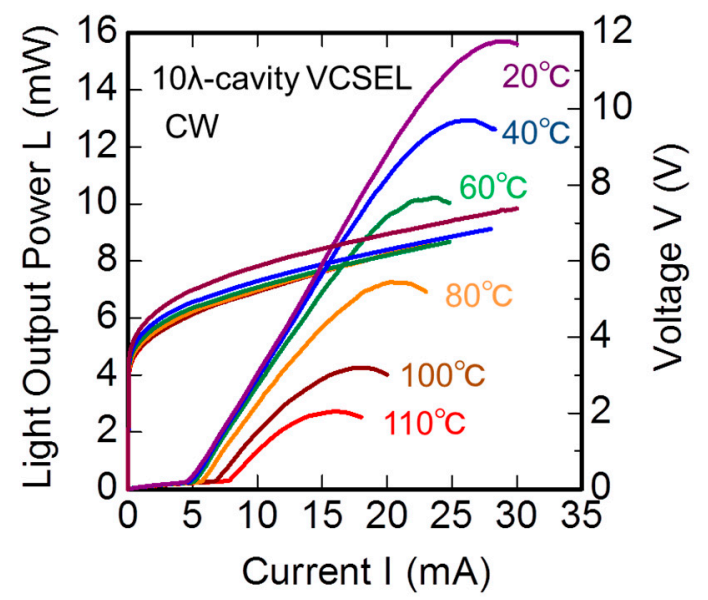

(b)

Figure 6. (a) I-L/I-V characteristics of the VCSEL having a 5- $\lambda$ cavity structure over a temperature range from 20 to $100{ }^{\circ} \mathrm{C}$. (b) I-L/I-V characteristics of the VCSEL having a 10- $\lambda$ cavity structure over the temperature range from 20 to $110^{\circ} \mathrm{C}$.

The I-L/I-V data acquired from the $10-\lambda$ cavity VCSEL from 20 to $110{ }^{\circ} \mathrm{C}$ are summarized in Figure $6 \mathrm{~b}$. These data demonstrate that the rollover operating current and maximum output power were both greatly increased as a result of this structure. An $\eta_{s}$ value of $0.87 \mathrm{~W} / \mathrm{A}$ together with an increased $\eta_{d}$ of $31 \%$ and an elevated output power of $15.7 \mathrm{~mW}$ were observed at $20^{\circ} \mathrm{C}$. The threshold voltage, threshold current density and threshold current at $20^{\circ} \mathrm{C}$ were $5.1 \mathrm{~V}, 9.0 \mathrm{kA} / \mathrm{cm}^{2}$ and $4.5 \mathrm{~mA}$, respectively. Relative to the $5 \lambda$-cavity analogue, a much higher rollover operating current was obtained ( 20 vs. $29 \mathrm{~mA}$ at $20^{\circ} \mathrm{C}$ ). This result can likely be ascribed to a lowering of the thermal resistance, together with a higher slope efficiency stemming from the reduced front mirror reflectivity [20]. 
Consequently, the light output power was close to double the original value at $20{ }^{\circ} \mathrm{C}$. The $10-\lambda$ cavity device showed a maximum wall-plug efficiency of $8.9 \%$ at $20^{\circ} \mathrm{C}$ together with an elevated lasing temperature of $110^{\circ} \mathrm{C}$ at an output power of $2.7 \mathrm{~mW}$ (see Figure $6 \mathrm{~b}$ ). This operating temperature together with a differential quantum efficiency of $31 \%$ and output power of $15.7 \mathrm{~mW}$ are, to our knowledge, the best results yet obtained from a GaN-based VCSEL in the CW mode.

The emission spectra acquired at current injection levels of $0.9 I_{t h}, 0.95 I_{t h}, I_{t h}$ and $1.05 I_{t h}$ from the VCSELs with both cavity structures are presented in Figure 7a,b. A significant increase in the peak intensities once a threshold value is exceeded is apparent in both figures. During CW operation at $20{ }^{\circ} \mathrm{C}$, the $5-\lambda$ and $10-\lambda$ cavity structures generated narrow $0.08 \mathrm{~nm}$ lasing linewidths at 443.5 and $440.1 \mathrm{~nm}$, respectively.

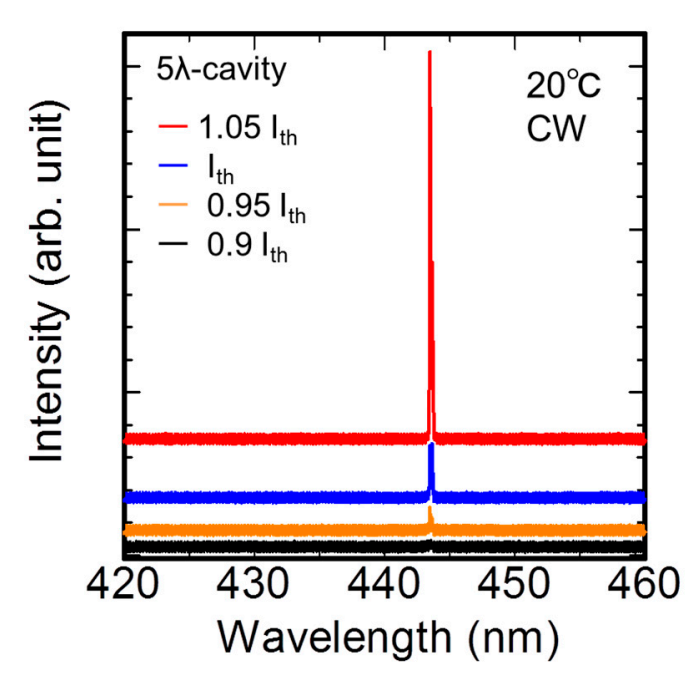

(a)

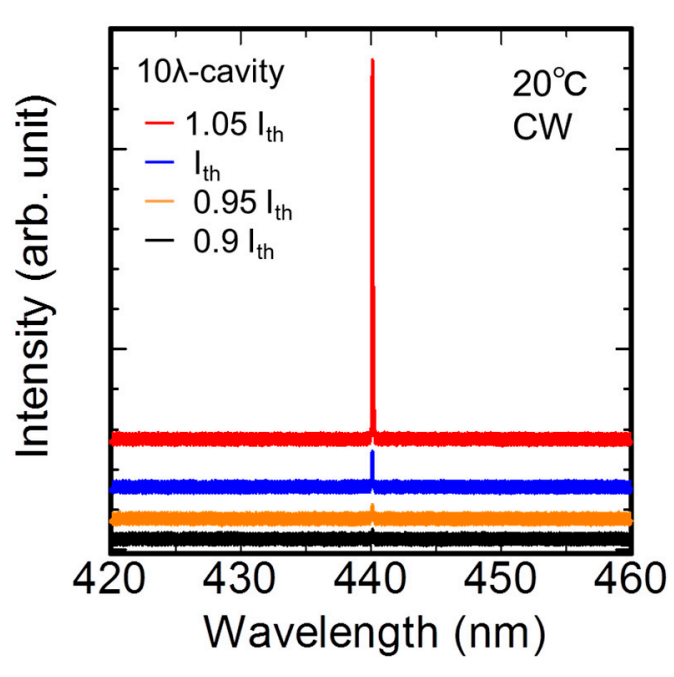

(b)

Figure 7. (a) Emission spectra of the VCSEL with a $5 \lambda$-cavity structure at different injection currents. A narrow peak wavelength at $443.5 \mathrm{~nm}$ was observed above the threshold. (b) Emission spectra of the VCSEL with a 10- $\lambda$ cavity structure at different injection currents. A narrow peak wavelength at $440.1 \mathrm{~nm}$ was observed above the threshold.

Incorporating a long cavity structure lowered the thermal resistance, and this effect was assessed by monitoring the thermal resistance $\left(R_{t h}\right)$ values. These values were obtained from experimental data via the equation:

$$
R_{t h}=\frac{\Delta T}{\Delta P_{\text {diss }}}=\frac{\frac{\Delta \lambda}{\Delta P_{\text {diss }}}}{\frac{\Delta \lambda}{\Delta T_{h s}}},
$$

where $\Delta \lambda / \Delta P_{\text {diss }}$ is the wavelength shift over the power dissipation value and $\Delta \lambda / \Delta T_{h s}$ is the wavelength shift over the variation in the heat sink temperature [34-37]. $\Delta \lambda / \Delta T_{h s}$ values from 0.012 to $0.0185 \mathrm{~nm} / \mathrm{K}$ have been previously reported for these types of devices [34,35,37,38]. Herein, thermal effects were negated by obtaining the $\Delta \lambda / \Delta T_{h s}$ data in conjunction with pulsed operation, and the $5 \lambda$ - and $10 \lambda$-cavity devices were determined to have values of 0.0142 and $0.0146 \mathrm{~nm} / \mathrm{K}$, respectively, which are in agreement with previously reported data. These same two VCSELs were found to have $\Delta \lambda / \Delta P_{\text {diss }}$ values of 0.015 and $0.0103 \mathrm{~nm} / \mathrm{mW}$, respectively, and $R_{\text {th }}$ values of 1100 and $710 \mathrm{~K} / \mathrm{W}$ were calculated based on Equation (4). The apparent increase of $65 \%$ in this value suggests an approximately 1.5 fold increase in the operating current at rollover, as seen in Figure $6 a, b$. This effect can be demonstrated by considering the 1.45 fold increase in the rollover operating current at $20{ }^{\circ} \mathrm{C}$ (from 20 to $29 \mathrm{~mA}$ ). It is therefore evident that lowering $R_{t h}$ increases the output power. Based on the theoretical evaluation of $R_{t h}$ in Ref. 35, this effect of lowering $R_{t h}$ in the present work is not 
unexpected, so it is apparent that increasing the n-GaN layer thickness enhances thermal dissipation within the VCSEL.

Using the power dissipation and $R_{t h}$, values of 159 and $161{ }^{\circ} \mathrm{C}$ were estimated for the internal temperature at rollover $\left(T_{i}^{\text {rollover }}\right)$ of the devices having $5 \lambda$ - and $10 \lambda$-cavity structures. The fact that these temperatures are quite close to one another demonstrates that a lower $R_{t h}$ value explains the increased output power of the $10 \lambda$-cavity unit. Therefore, obtaining the maximum possible lasing

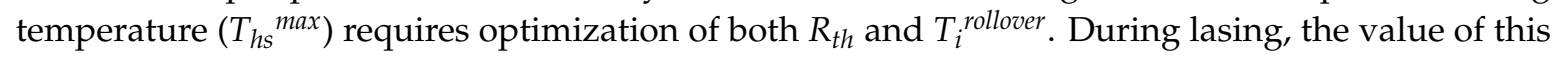
parameter can be written as:

$$
T_{h s}^{\max }<T_{i}^{\text {rollover }}-R_{\text {th }} \times P_{\text {diss }}^{\text {threshold }} \approx T_{i}^{\text {rollover }}-R_{t h} \times I_{t h} \times V_{t h} .
$$

where, $P_{\text {diss }}$ threshold is the threshold power dissipation while $I_{t h}$ and $V_{\text {th }}$ are the threshold current and voltage. Therefore, the effect of temperature on $I_{t h}$ is a primary factor with regard to the magnitude of $T_{h s}{ }^{\max }$. The threshold currents are plotted as functions of temperature in Figure 8. It is evident from these data that the effect of temperature on $I_{\text {th }}$ was small from 293 to $333 \mathrm{~K}$, and that the $10 \lambda$-cavity VCSEL showed a comparatively elevated characteristic temperature $\left(T_{0}=316 \mathrm{~K}\right)$. Conversely, the $I_{t h}$ value was increased rapidly as the temperature was increased above $330 \mathrm{~K}$. This trend greatly increased the internal temperature of the VCSEL at high temperatures but below the threshold, such that the device exhibited a maximum lasing temperature of $110^{\circ} \mathrm{C}$. The VCSEL threshold current is determined by the degree of mismatch between the peak gain and the cavity mode wavelength. Thus, the optimal extent of lasing mode detuning as a result of temperature changes is required for each specific application [39].

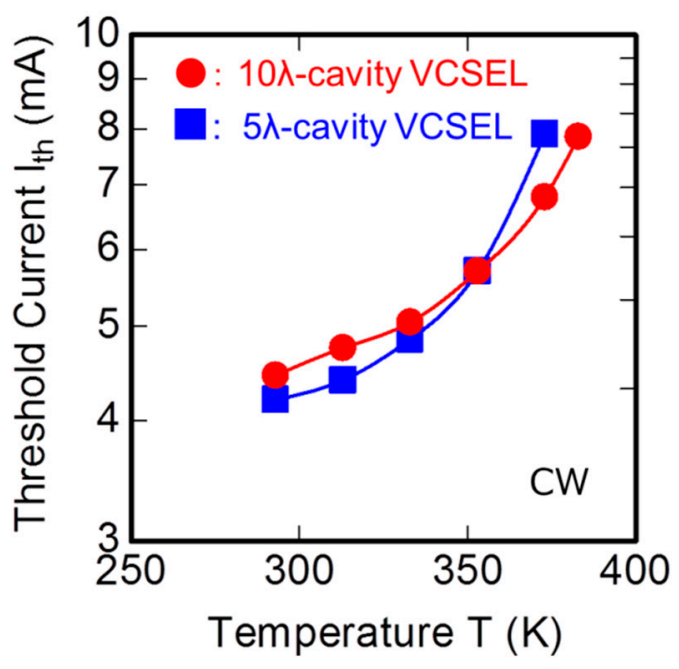

Figure 8. Temperature dependence of the threshold current under CW operation.

The long-cavity structure strongly affects not only the thermal resistance but also the transverse mode in VCSELs because the normalized effective index difference $\left(\Delta n_{\text {eff }} / n\right)$ decreases even for $\mathrm{SiO}_{2}$-buried layers of the same thickness in Figure $2 \mathrm{~b}$, and the diffraction loss of higher-order-modes increases, compared to the short-cavity structure. Furthermore, the thermal lens effect in the long-cavity structure must fade off at the same dissipated power because of the change in the thermal resistance. In general, low divergent output beams are preferred for many applications because they allow for the use of simple optics and exhibit high brightness. Yeh et al. have demonstrated a small full width at half maximum (FWHM) divergence angle of approximately $5^{\circ}$ in a GaN-based VCSEL with a 3- $\mu \mathrm{m}$ aperture Si-diffusion-defined confinement structure [40]. The FFP and I-L characteristics at low power of small aperture VCSELs were also assessed so as to examine variations in the mode patterns beam divergence between the $10 \lambda$ - and $5 \lambda$-cavity VCSELs. The I-L plots obtained from both types of device having $5.5 \mu \mathrm{m}$ apertures during $\mathrm{CW}$ operation at $20^{\circ} \mathrm{C}$ are presented in Figure 9 a. 
These data demonstrate that the $5 \lambda$-cavity VCSEL exhibited a maximum power, threshold current density and threshold current of $6.6 \mathrm{~mW}, 9.7 \mathrm{kA} / \mathrm{cm}^{2}$ and $2.3 \mathrm{~mA}$, respectively. The smaller aperture size gives a lower threshold current and maximum power due to the volume effect, compared to the 8- $\mu \mathrm{m}$ aperture VCSEL in Figure $6 \mathrm{a}$. This tendency is the same for the 10- $\lambda$ cavity VCSEL. From Figure $9 \mathrm{a}$, the threshold current, threshold current density and maximum power of the 10- $\lambda$ cavity VCSEL were $2.8 \mathrm{~mA}, 11.7 \mathrm{kA} / \mathrm{cm}^{2}$ and $12.5 \mathrm{~mW}$, respectively. These data also indicate that the high power performance of the 10- $\lambda$ cavity VCSEL is superior to that of the $5 \lambda$-cavity VCSEL with a small aperture due to the improvement in the thermal resistance.

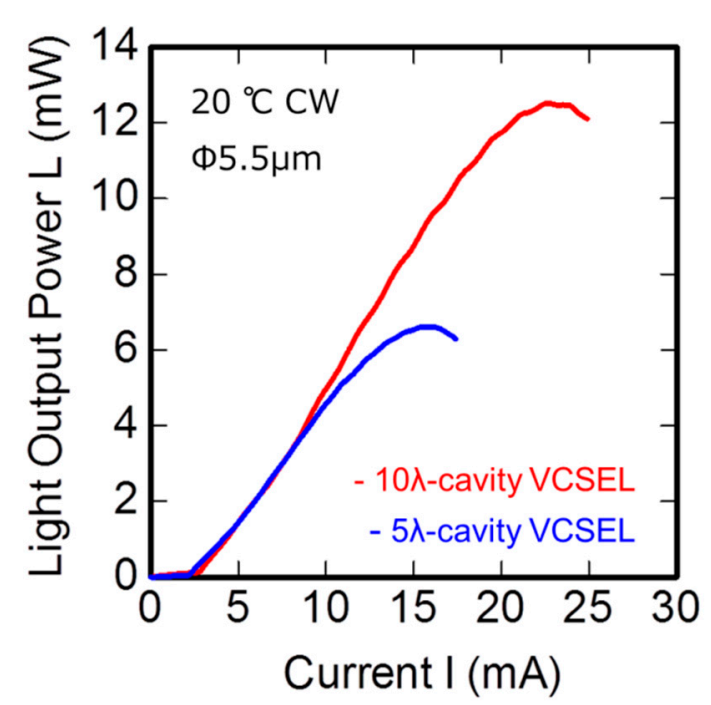

(a)

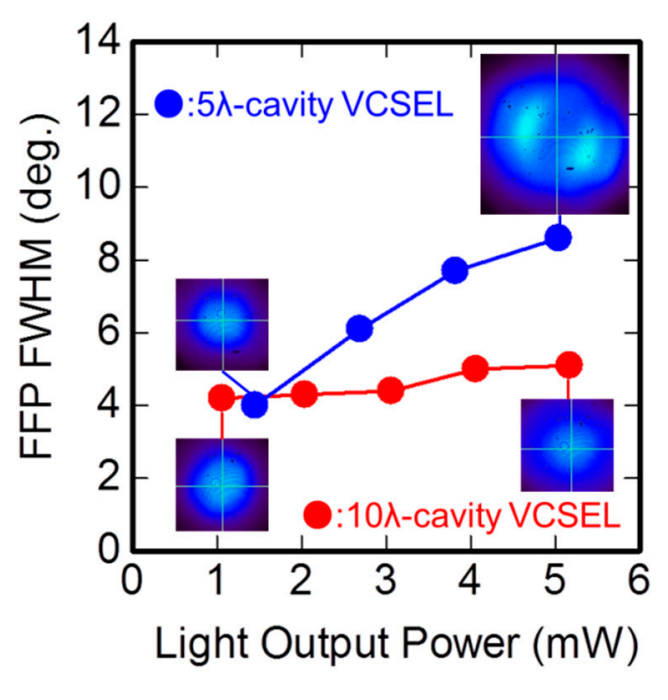

(b)

Figure 9. (a) I-L characteristics of the $5 \lambda$ - and $10 \lambda$-cavity VCSELs with $5.5-\mu \mathrm{m}$ aperture under $\mathrm{CW}$ operation at $20^{\circ} \mathrm{C}$. (b) Full width at half maximum (FWHM) of far field pattern (FFP) of the $5 \lambda$ - and $10-\lambda$ cavity VCSELs with $5.5-\mu \mathrm{m}$ aperture as a function of light output power. The insets show the FFP images at around $1 \mathrm{~mW}$ and $5 \mathrm{~mW}$.

Figure $9 \mathrm{~b}$ shows the FWHM divergence angle of the $5 \lambda$ - and 10 $\lambda$-cavity VCSELs with $5.5-\mu \mathrm{m}$ aperture as a function of their LOP. The insets show the FFP images at around $1 \mathrm{~mW}$ and $5 \mathrm{~mW}$.

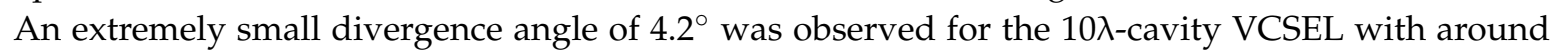
$1 \mathrm{~mW}$. Furthermore, a narrow beam of $5.1^{\circ}$ in FFP angle was observed even at a relatively high LOP of $5 \mathrm{~mW}$, as shown in Figure 9b. The FFP image of the $5 \lambda$-cavity VCSEL at $5 \mathrm{~mW}$, on the other hand, was clearly different and shows a doublet multi-mode shape, although a small divergence angle of $4^{\circ}$ was observed at around $1 \mathrm{~mW}$. In this case, the divergence angle gradually spread out with an increase in LOP, indicating that the component of the higher-order-mode became dominant due to spatial refractive index changes, such as spatial hole burning and thermal lens effects. The improvement of thermal resistance and the large asymmetry of the mirror design possibly suppressed the spatial refractive index change in the $10 \lambda$-cavity VCSEL. It is very interesting that such high power technologies established by edge emitting lasers are also effective in GaN-based VCSELs.

\section{Conclusions}

In conclusion, we have demonstrated a blue GaN-based VCSEL featuring a $\mathrm{SiO}_{2}$-buried LOC structure, in which the reflectivity can be tuned by varying the AlInN/GaN DBR. Without the LOC structure, a conventional GaN-based VCSEL exhibits an extremely high transverse radiation loss, shown by internal loss measurements. The internal loss was significantly reduced by introducing the $\mathrm{SiO}_{2}$-buried LOC configuration. This decrease in the internal loss, combined with an adjustment of the 
cavity mirror reflectivity, resulted in the highest slope efficiency value so far recorded of $0.87 \mathrm{~W} / \mathrm{A}$ and the highest $\eta_{d}{ }^{\text {total }}$ of $32 \%$ under pulsed operation, in addition to a maximum output power of $6 \mathrm{~mW}$ under $\mathrm{CW}$ operation. It is evident that controlling the cavity mirror and lowering the internal loss are both important with regard to increasing external differential quantum efficiency, slope efficiency and output power. On this basis, the present study obtained output power values of 15.7 and $2.7 \mathrm{~mW}$ at 20 and $110^{\circ} \mathrm{C}$, respectively. These represent the highest power values reported to date for a blue VCSEL based on GaN, and were achieved by reducing the reflectivity of the front cavity mirror to $99.1 \%$ while incorporating a long $(10 \lambda)$ structure. The thermal resistance of the device relative to that of a $5 \lambda$ analogue was lowered from 1100 to $710 \mathrm{~K} / \mathrm{W}$, and these VCSELs were found to exhibit an elevated internal temperature of $434 \mathrm{~K}$ at their rollover point. Tuning the front mirror reflectivity in conjunction with these other modifications improved the device performance, giving an $8.9 \%$ wall-plug efficiency, $31 \%$ differential efficiency and an output power of $15.7 \mathrm{~mW}$ at $20^{\circ} \mathrm{C}$. In transverse mode control,

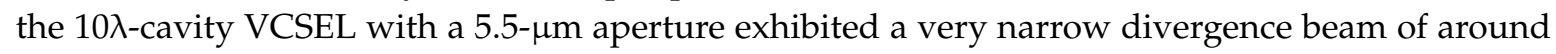
$5^{\circ}$ even at around $5 \mathrm{~mW}$ output power. These technologies and their superior performances may open the door to the practical use of VCSEL eyewear display. In a future study, we will investigate a W-class high-power VCSEL array in the blue wavelength range, with potential use in highly functional automotive headlamps.

Author Contributions: Conceptualization and device design, M.K.; epitaxial growth, T.A. and K.T. (Kazufumi Tanaka); fabrication process, S.K. and K.T. (Komei Tazawa); measurement and evaluation, M.K. and K.T. (Komei Tazawa); project administration, T.S.; supervision, T.T.; writing and original draft preparation, M.K.; writing, review and editing, T.T. and M.K.

Funding: This research received no external funding.

Acknowledgments: The authors thank Y. Kawakami, S. Tanaka, Y. Yokobayashi, S. Kubo, K. Takashima, K. Nakata and K. Kiyohara for their support during fabrication of the device and for helpful discussions. We also thank T. Tanabe and J. Sonoda for their encouragement during this work.

Conflicts of Interest: The authors declare no conflict of interest.

\section{References}

1. Hoshino, S.; Kita, Y.; Uchida, M.; Mori, T.; Kimura, Y.; Harata, S.; Saito, T.; Yatsuda, Y. Challenges for the laser scanning headlamps to realize safe driving experience. In Proceedings of the 12th International Symposium on Automotive Lighting; München Herbert Utz Verlag GmbH: München, Germany, 2017; Volume 17, pp. $299-305$.

2. Hager, J.; Seitz, M.; Bemmer, C.; Jahn, P.; Ansorg, P.; Woisetschlager, O.; Buchmann, F.; Sprenger, D.; Vogl, M.; Hering, O.; et al. Handling 17W of scanning laser power-Three years of exploration in the iLaS project. In Proceedings of the 12th International Symposium on Automotive Lighting; München Herbert Utz Verlag GmbH: München, Germany, 2017; Volume 17, pp. 271-280.

3. Stroop, P.; Hilling, B.; Steudel, F.; Nolte, P. LASER scanning lighting systems-Optimization of contrast and further challenges. In Proceedings of the SIA VISION, Paris, France, 9-10 October 2018; Volume 2018, pp. 167-172.

4. Lu, T.C.; Kao, C.C.; Kuo, H.C.; Huang, G.S.; Wang, S.C. CW lasing of current injection blue GaN-based vertical cavity surface emitting laser. Appl. Phys. Lett. 2008, 15, 141102. [CrossRef]

5. Higuchi, Y.; Omae, K.; Matsumura, H.; Mukai, T. Room-Temperature CW Lasing of a GaN-Based Vertical-Cavity Surface-Emitting Laser by Current Injection. Appl. Phys. Express 2008, 1, 121102. [CrossRef]

6. Lu, T.C.; Chen, S.W.; Wu, T.T.; Tu, P.M.; Chen, C.K.; Chen, C.H.; Li, Z.Y.; Kuo, H.C.; Wang, S.C. Continuous wave operation of current injected $\mathrm{GaN}$ vertical cavity surface emitting lasers at room temperature. Appl. Phys. Lett. 2010, 97, 071114. [CrossRef]

7. Kasahara, D.; Morita, D.; Kosugi, T.; Nakagawa, K.; Kawamata, J.; Higuchi, Y.; Matsumura, H.; Mukai, T. Demonstration of Blue and Green GaN-Based Vertical-Cavity Surface-Emitting Lasers by Current Injection at Room Temperature. Appl. Phys. Express 2011, 4, 072103. [CrossRef]

8. Onishi, T.; Imafuji, O.; Nagamatsu, K.; Kawaguchi, M.; Yamanaka, K.; Takigawa, S. Continuous Wave Operation of GaN Vertical Cavity Surface Emitting Lasers at Room Temperature. IEEE J. Quantum Electron. 2012, 48, 1107-1112. [CrossRef] 
9. Liu, W.-J.; Hu, X.-L.; Ying, L.Y.; Zhang, J.-Y.; Zhang, B.-P. Room temperature continuous wave lasing of electrically injected GaN-based vertical cavity surface emitting lasers. Appl. Phys. Lett. 2014, 104, 251116. [CrossRef]

10. Izumi, S.; Fuutagawa, N.; Hamaguchi, T.; Murayama, M.; Kuramoto, M.; Narui, H. Room-temperature continuous-wave operation of GaN-based vertical-cavity surface-emitting lasers fabricated using epitaxial lateral overgrowth. Appl. Phys. Express 2015, 8, 062702. [CrossRef]

11. Furuta, T.; Matsui, K.; Horikawa, K.; Ikeyama, K.; Kozuka, Y.; Yoshida, S.; Akagi, T.; Takeuchi, T.; Kamiyama, S.; Iwaya, M.; et al. Room-temperature CW operation of a nitride-based vertical-cavity surface-emitting laser using thick GaInN quantum wells. Jpn. J. Appl. Phys. 2016, 55, 05FJ11. [CrossRef]

12. Hsieh, D.H.; Tzou, A.J.; Kao, T.S.; Lai, F.I.; Lin, D.W.; Lin, B.C.; Lu, T.C.; Lai, W.C.; Chen, C.H.; Kuo, H.C. Improved carrier injection in GaN-based VCSEL via AlGaN/GaN multiple quantum barrier electron blocking layer. Opt. Express 2015, 23, 27145-27151. [CrossRef]

13. Hamaguchi, T.; Fuutagawa, N.; Izumi, S.; Murayama, M.; Narui, H. Milliwatt-class GaN-based blue vertical-cavity surface-emitting lasers fabricated by epitaxial lateral overgrowth. Phys. Status Solidi A 2016, 213, 1-7. [CrossRef]

14. Hayashi, N.; Ogimoto, J.; Matsui, K.; Furuta, T.; Akagi, T.; Iwayama, S.; Takeuchi, T.; Kamiyama, S.; Iwaya, M.; Akasaki, I. A GaN-Based VCSEL with a Convex Structure for Optical Guiding. Phys. Status Solidi 2018, 215, 1700648. [CrossRef]

15. Takeuchi, T.; Kamiyama, S.; Iwaya, M.; Akasaki, I. GaInN VCSELs with AlInN/GaN DBRs. In Proceedings of the International Conference on Nitride Semiconductors, Strasbourg, France, 24-28 July 2017.

16. Yu, H.C.; Zheng, Z.W.; Mei, Y.; Xu, R.B.; Liu, J.P.; Yang, H.; Zhang, B.P.; Lu, T.C.; Kuo, H.C. Progress and prospects of GaN-based VCSEL from near UV to green emission. Prog. Quantum Electron. 2018, 57, 1-19. [CrossRef]

17. Cosendey, G.; Castiglia, A.; Rossbach, G.; Carin, J.F.; Grandjean, N. Blue monolithic AlInN-based vertical cavity surface emitting laser diode on free-standing GaN substrate. Appl. Phys. Lett. 2012, 101, 151113. [CrossRef]

18. Leonard, J.T.; Young, E.C.; Yonkee, B.P.; Cohen, D.A.; Margalith, T.; Denbaars, S.P.; Speck, J.S.; Nakamura, S. Demonstration of a III-nitride vertical-cavity surface-emitting laser with a III-nitride tunnel junction intracavity contact. Appl. Phys. Lett. 2015, 107, 091105. [CrossRef]

19. Xu, R.; Mei, Y.; Xu, H.; Ying, L.Y.; Zheng, Z.; Long, H.; Zhang, D.; Zhang, B.; Liu, J. Green Vertical-Cavity Surface-Emitting Lasers Based on Combination of Blue-Emitting Quantum Wells and Cavity-Enhanced Recombination. IEEE Trans. Electr. Devices 2018, 65, 4401-4406. [CrossRef]

20. Kuramoto, M.; Kobayashi, S.; Akagi, T.; Tazawa, K.; Tanaka, K.; Saito, T.; Takeuchi, T. Enhancement of slope efficiency and output power in GaN-based vertical-cavity surface-emitting lasers with a SiO2-buried lateral index guide. Appl. Phys. Lett. 2018, 112, 111104. [CrossRef]

21. Kuramoto, M.; Kobayashi, S.; Akagi, T.; Tazawa, K.; Tanaka, K.; Saito, T.; Takeuchi, T. High-output-power and high-temperature operation of blue GaN-based vertical-cavity surface-emitting laser. Appl. Phys. Express 2018, 11, 112101. [CrossRef]

22. Ellafi, D.; Iakovlev, V.; Sirbu, A.; Grigore, S.; Mickovic, Z.; Caliman, A.; Mereuta, A.; Kapon, E. Effect of Cavity Lifetime Variation on the Static and Dynamic Properties of 1.3- $\mu \mathrm{m}$ Wafer-Fused VCSELs. IEEE J. Sel. Top. Quantum Electron. 2015, 21, 1700509. [CrossRef]

23. Hashemi, E.; Bengtsson, J.; Gustavsson, J.; Stattin, M.; Cosendey, G.; Grandjean, N.; Haglund, A. Analysis of structurally sensitive loss in GaN-based VCSEL cavities and its effect on modal discrimination. Opt. Express 2014, 22, 411-426. [CrossRef]

24. Hadley, G.R. Effective index model for vertical-cavity surface-emitting lasers. Opt. Lett. 1995, 20, 1483-1485. [CrossRef]

25. Michalzik, R. VCSELs, Springer Series in Optical Science; Springer: Berlin, Germany, 2013; Volume 166, p. 38.

26. Kuksenkov, D.V.; Temkin, H.; Swirthun, S. Measurement of internal quantum efficiency and losses in vertical cavity surface emitting lasers. Appl. Phys. Lett. 1995, 66, 1720-1722. [CrossRef]

27. Westbergh, P.; Gustavsson, J.S.; Kogel, B.; Haglund, A.; Larsson, A. Impact of Photon Lifetime on High-Speed VCSEL Performance. IEEE J. Sel. Top. Quantum Electron. 2011, 17, 1603-1613. [CrossRef]

28. Koyama, F.; Suematsu, Y.; Arai, S.; Tawee, T. 1.5-1.6 $\mu \mathrm{m}$ GaInAsP/InP dynamic-single-mode (DSM) lasers with distributed Bragg reflector. IEEE J. Quantum Electron. 1983, QE-19, 1042-1051. [CrossRef] 
29. Tong, H.; Zhang, J.; Liu, G.; Herbsommer, J.A.; Huang, G.S.; Tansu, N. Thermoelectric properties of lattice-matched AlInN alloy grown by metal organic chemical vapor deposition. Appl. Phys. Lett. 2010, 97, 112105. [CrossRef]

30. Zhang, J.; Tong, H.; Liu, G.; Herbsommer, J.A.; Huang, G.S.; Tansu, N. Characterizations of Seebeck coefficients and thermoelectric figures of merit for AlInN alloys with various In-contents. J. Appl. Phys. 2011, 109, 053706. [CrossRef]

31. Zou, J.; Kotchetkov, D.; Balandin, A.A.; Florescu, D.I.; Pollak, H. Thermal conductivity of GaN films: Effects of impurities and dislocations. J. Appl. Phys. 2002, 92, 2534-2539. [CrossRef]

32. Shibata, H.; Waseda, Y.; Ohta, H.; Kiyomi, K.; Shimoyama, K.; Fujito, K.; Nagaoka, H.; Kagamitani, Y.; Simura, R.; Fukuda, T. High Thermal Conductivity of Gallium Nitride (GaN) Crystals Grown by HVPE Process. Mater. Trans. 2007, 48, 2782-2786. [CrossRef]

33. Mishkat-UI-Masabih, S.; Leonard, J.; Cohen, D.; Nakamura, S.; Feezell, D. Techniques to reduce thermal resistance in flip-chip GaN-based VCSELs. Phys. Status Solidi A 2017, 214, 1600819. [CrossRef]

34. Chang, T.-C.; Kuo, S.-Y.; Lian, J.-T.; Hong, K.-B.; Wang, S.-C.; Lu, T.-C. High-temperature operation of GaN-based vertical-cavity surface-emitting lasers. Appl. Phys. Express 2017, 10, 112101. [CrossRef]

35. Mei, Y.; Xu, R.-B.; Xu, H.; Ying, L.-Y.; Zheng, Z.-W.; Zhang, B.-P.; Li, M.; Zhang, J. A comparative study of thermal characteristics of GaN-based VCSELs with three different typical structures. Semicond. Sci. Technol. 2018, 33, 015016. [CrossRef]

36. Michalzik, R. VCSELs, Springer Series in Optical Science; Springer: Berlin, Germany, 2013; Volume 166, p. 19.

37. Lu, T.-C.; Wu, T.-T.; Chen, S.-W.; Tu, P.-M.; Li, Z.-Y.; Chen, C.-K.; Chen, C.-H.; Kuo, H.-C.; Wang, S.-C.; Zan, H.-W.; et al. Characteristics of Current-Injected GaN-Based Vertical-Cavity Surface-Emitting Lasers. IEEE J. Sel. Top. Quantum Electron. 2011, 17, 1594-1601.

38. Holder, C.O.; Leonard, J.T.; Farrell, R.M.; Cohen, D.A.; Yonkee, B.; Speck, J.S.; Denbaars, S.P.; Nakamura, S.; Feezell, D.F. Nonpolar III-nitride vertical-cavity surface emitting lasers with a polarization ratio of $100 \%$ fabricated using photoelectrochemical etching. Appl. Phys. Lett. 2014, 105, 031111. [CrossRef]

39. Lu, B.; Zhou, P.; Cheng, J.; Malloy, J.; Zolper, J.C. High temperature pulsed and continuous-wave operation and thermally stable threshold characteristics of vertical-cavity surface-emitting lasers grown by metalorganic chemical vapor deposition. Appl. Phys. Lett. 1994, 65, 1337-1339. [CrossRef]

40. Yeh, P.S.; Chang, C.-C.; Chen, Y.-T.; Lin, D.-W.; Liou, J.-S.; Wu, C.C.; He, J.H.; Kuo, H.-C. GaN-based vertical-cavity surface emitting lasers with sub-milliamp threshold and small divergence angle. Appl. Phys. Lett. 2016, 109, 241103. [CrossRef] 